\title{
Utilization of Nanosized Carbamoylethyl Cellulose in Preparation of Copper Nanoparticles
}

\author{
Th.I. Shaheen*, S. Farag, S. Sharaf, and A. Hebeish \\ Textile Research Division, National Research Centre, Dokki, Cairo, Egypt
}

\begin{abstract}
CURRENTLY, much attention is paid to the development of efficient green materials derived from renewable resources characterized by biodegradability and non-toxicity to neither human nor environment. In this study, nano-carbamoylethyl cellulose (NCEC) with D.S. of 0.8 and size of ca $37 \mathrm{~nm}$ was harnessed for preparation and stabilization of copper nanoparticles (CuNPs). To achieve the goal, NCEC acted as stabilizing agent during the synthesis of CuNPs. Indeed, CuNPs were produced in spherical shape with small sizes in range of $25 \mathrm{~nm}$ as signified by UV-vis spectroscopy and TEM. Nevertheless, the colloidal solutions of CuNPs at different concentrations exhibited extremely high stability.
\end{abstract}

Keywords: Nanostructure; Carbamoylethyl cellulose; Cellulose nanocrystals; Copper nanoparticles.

\section{Introduction}

Most recently, green materials have gained much more attention as renewable sources featured by their biodegradability and nontoxicity to humans and environment [1-5]. One of the most naturally existed in the earth is cellulose, which is a biopolymer possesses these features. In this manner, nanomaterials have similar interesting due to their unique properties which are differ than those existed in the bulk state. Many applications of nanoparticulated materials have been developed last years such as reinforcement in polymeric matrixes, composites and nanocomposites processing. Of these nanomaterials is cellulose nanocrystals (CNC), which offering novel characters able to utilized over industrial scale. Regarding to previous works, CNC is also identified by idioms whisker, nanofiber, cellulose crystallite or crystal. It represents the crystalline region in the micro-structure of cellulosic fibers. Extraction of these crystals is commonly conducted by acid hydrolysis treatment which dissolves the amorphous regions and lefts the crystals in suspension form. Consequently, $\mathrm{CNC}$ has been evoked through multidiscipline fields as dint of their physical characteristics including stiffness, thickness, and length [3, 6-8].
In particular, there are great efforts of research and technical work have been moved towards fabrication of different nanomaterials through employing of green approaches for optimal harnessing of their unprecedent properties such as electrical conductivity and antimicrobial activity as well as cost-effective [9-11]. Preparation metal nanoparticles sometimes impose the necessity of inducing certain modifications to cellulose crystals which are unique with respect to biocompatibility, edibility, abundance in nature, excellent barrier properties and low cost [12]. Besides, CuNPs has a tendency to be oxidized to $\mathrm{Cu}^{+}$and $\mathrm{Cu}^{+2}$ ions at ambient temperature. NCEC may introduce a suitable solution to improve the stability of CuNPs at ambient temperature [13-15]. By virtue of their good conductive properties, $\mathrm{CNC}$ as well as their modifications have stimulated the interest of many researchers wide-world. The applications encompass, interalia, the production of textiles with new properties such as conductivity which is rather a new field being investigated [16]. Current work has been designed to harness the new member NCEC as a precursor for preparation of CuNPs with high stability instead of synthetic polymers.

*Corresponding Authors: shaheen_chem@yahoo.com

DOI: $10.21608 /$ jtcps.2019.18487.1029 


\section{Experimental}

\section{Materials and methods}

NCEC has been prepared according to our previous work. While, copper acetate, ascorbic acid and ethylene glycol were all of laboratory grade chemicals.

\section{Preparation of CuNPs}

The experimental procedure for preparation of copper nanoparticles (CUNPs) using NCEC were performed as per two steps. In step one, $1.0 \mathrm{gm}$ NCEC was dissolved in $50 \mathrm{ml}$ distilled water in order to obtain uniform solution of NCEC, then, $0.1 \mathrm{~N}$ of $\mathrm{NaOH}$ was added to solution to raise the $\mathrm{pH}$ to 10 . Copper acetate $\mathrm{Cu}\left(\mathrm{OCOCH}_{3}\right)_{2}$ was dissolved in little amount of distilled water and added drop-wise to the solution while vigorously stirring under the action of magnetic stirrer. Also, in the first step, ascorbic acid $\left(\mathrm{C}_{6} \mathrm{H}_{8} \mathrm{O}_{6}\right)$ was added to the aqueous solution of NCEC containing copper. The second step includes addition of 0.1 $\mathrm{M} \mathrm{NaBH}$ to this solution under rapid stirring. This is followed by addition of ethylene glycol to get $100 \mathrm{ml}$ net volume of solution. Finally, the temperature was raised to the extent that it reached $120{ }^{\circ} \mathrm{C}$. The color changed gradually from green to red indicating that copper nanoparticles were generated.

\section{Analysis and characterization}

Ultra Violet-Visible (UV-vis) spectra

$\mathrm{UV}$-vis spectra have been proved to be quite sensitive to the formation of silver and copper colloids because they exhibit an intense absorption peak due to the Surface Plasmon Excitation. Hence, silver and copper colloids were recorded in spectrophotometer from 300-700nm.

\section{Transmission Electron Microscope (TEM)}

The morphology of the as formed CuNPs was characterized using Transmission Electron Microscopy (TEM) (JEOL 1200, JEOL USA, Inc) with an accelerating voltage of $80 \mathrm{kV}$. The $0.1 \mathrm{wt} \%$ nano-crystal suspensions dropped onto copper grids coated with a carbon support film.

\section{Results and discussion}

One of the intersting applications is the use of cellulose nanostructures as a template and stabilizer for metal nanoparticles during thier synthesis [17]. In this regard, the concurrent comparitive study divulges the effeciency of NCEC as a novel template in course of copper nanoparticles.
NCEC was used as stabilizing agent through chelation of copper ions with $\mathrm{NH}_{2}$ and $-\mathrm{COOH}$ groups present along the etherified chains of NCEC. One the other hand, the reduction involved two stages, the first includes reduction of $\mathrm{Cu}^{+2}$ to $\mathrm{Cu}^{+1}$ after addition of the antioxidant ascorbic acid to solution of $\mathrm{Cu}-\mathrm{NCEC}$ complex, whereby, the blue color of copper acetate changed, immediately, to yellow color due to $\mathrm{Cu}_{2} \mathrm{O}$ formation. Second stage, upon addition of $\mathrm{NaBH}_{4}$ the color changed from yellow to violet which calls for the presence of both $\mathrm{Cu}_{2} \mathrm{O}$ and $\mathrm{Cu}$ metal. After raising of temperature to $120{ }^{\circ} \mathrm{C}$, the color of colloid changes to dark red, indicating formation of $\mathrm{Cu}$ nanoparticles. Routinely, UVvis spectroscopy was used for monitoring the reduction of copper ions to copper nanoparticles. Accordingly, the characteristics absorption peak for copper nanoparticles is in the range of 550 $600 \mathrm{~nm}$ [18-22] as shown in Figure 1.

Figure 1 shows the UV-vis spectra of CuNPs prepared using $0.075 \mathrm{gm}$ of copper acetate, which indicates that the absorption peak is highly broadening with low absorbance. The broaden peak is accompanied with shifting in the plasmon resonance toward longer wavelength which occurs at $c a 585 \mathrm{~nm}$. This refers to low reduction of $\mathrm{Cu}^{+}$ ions to $\mathrm{Cu}^{0}$, which gives rise to form big size of CuNPs formation. The reduction efficiency is believed to be due to the availability of chelated copper ions with stabilizing agent (NCEC) for reduction. Low reduction efficiency observed with CuNPs could be attributed to poor chelation property of NCEC. The results explain the poor stability of copper nanoparticles prepared from NCEC using $0.075 \mathrm{gm}$ of copper acetate. Here the color changes immediately from red to yellow indicating formation of $\mathrm{Cu}_{2} \mathrm{O}$.

On the other hand, preparation of copper nanoparticles through decreasing the concentration of copper acetate to $0.05 \mathrm{gm}$, while other additives remain the same, reveals that sharp and intense absorption peak occurs at wavelength $570 \mathrm{~nm}$. These observations make it evident that, copper nanoparticles were formed successfully, from NCEC at low concentration of $\mathrm{Cu}^{+}$ion with smaller sizes. The size of the so-formed CuNPs was determined using TEM. Figure 2 illustrates TEM micrograph and histogram showing particle size and size distribution of copper nanoparticles prepared using NCEC along with $0.05 \mathrm{gm}$ copper acetate. 


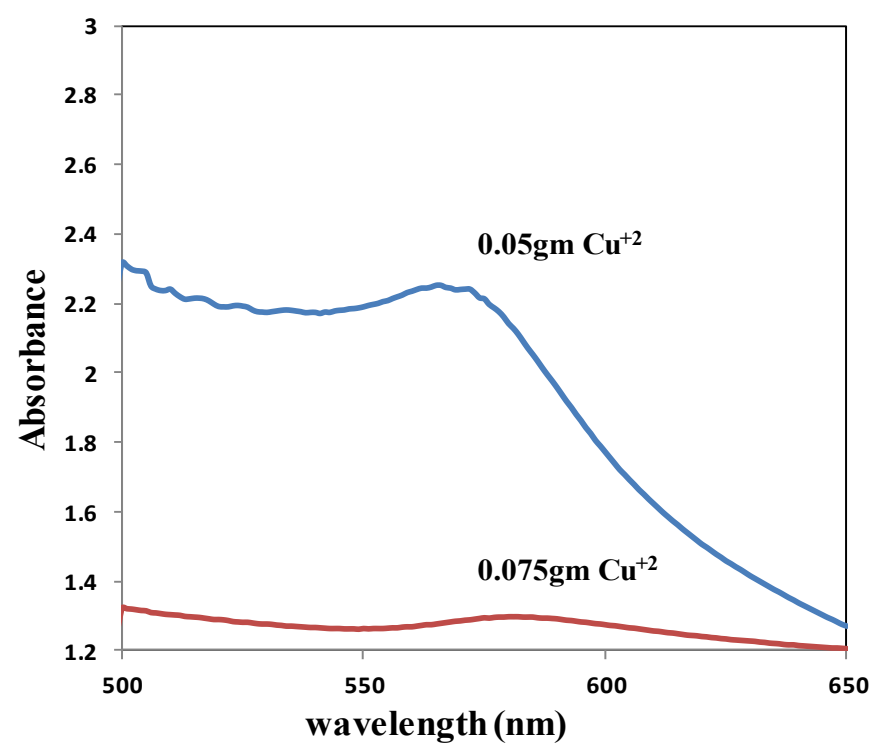

Fig. 1. UV-vis spectroscopy of copper nanoparticles prepared using two different concentrations of copper acetate; $0.075 \mathrm{gm}$ and $0.05 \mathrm{gm}, 1.0 \mathrm{gm}$ of $\mathrm{NCEC}, 0.75 \mathrm{gm}$ of ascorbic acid, $0.1 \mathrm{~N} \mathrm{NaOH}, 0.1 \mathrm{M} \mathrm{NaBH}_{4}$ and ethylene glycol in $100 \mathrm{ml}$ solution at $120^{\circ} \mathrm{C}$.
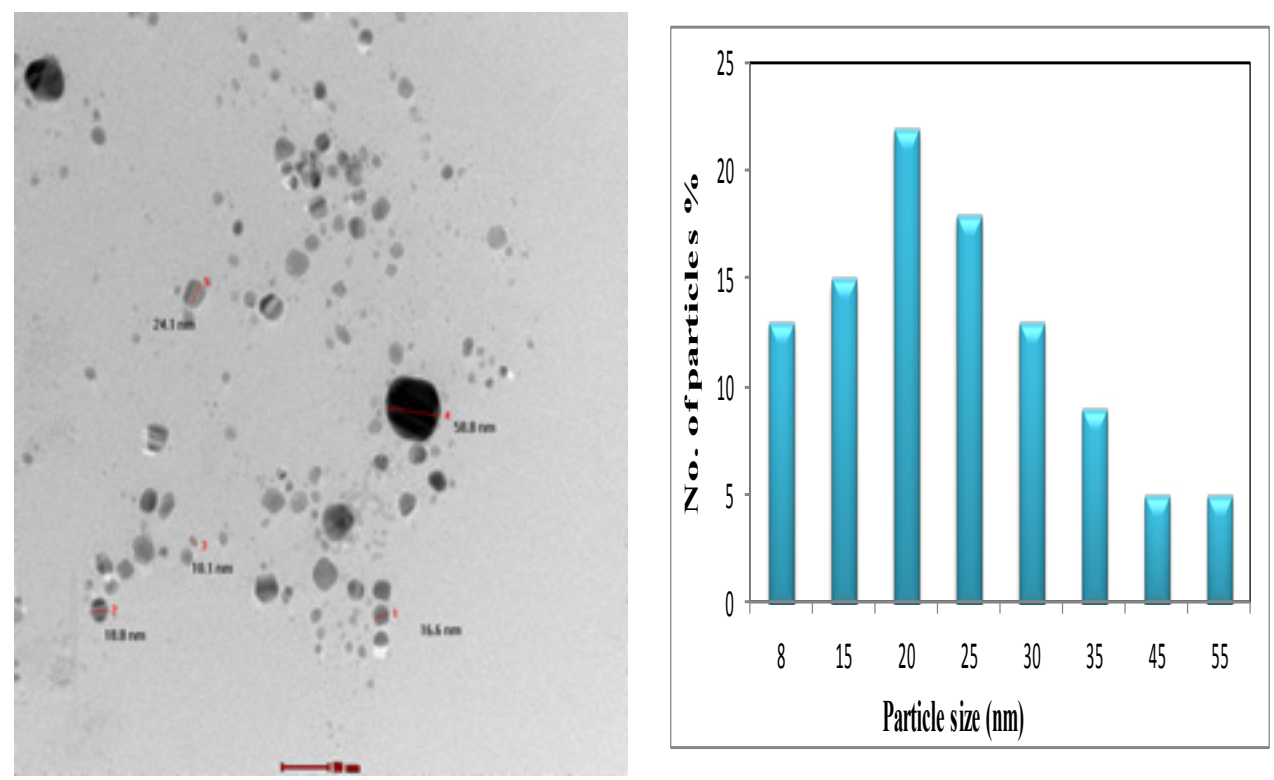

Fig. 2. TEM micrograph and histogram of copper nanoparticles prepared using $0.05 \mathrm{gm}$ copper acetate, $1.0 \mathrm{gm}$ of NCEC, $0.75 \mathrm{gm}$ of ascorbic acid, $0.1 \mathrm{~N} \mathrm{NaOH}, 0.1 \mathrm{M} \mathrm{NaBH} 4$ and ethylene glycol in $100 \mathrm{ml}$ solution at $1200 \mathrm{C}$. 
Figure 2 shows that particle size, ranging from 8 to $55 \mathrm{~nm}$, acquire a wide size distribution, but the majority of them are dispersed within a narrow range between $15-30 \mathrm{~nm}$. Based on the foregoing, a number of important findings may be emphasized; 1) NCEC has limited chelation potency toward higher concentration of copper acetate such as $0.075 \mathrm{gm} ; 2$ ) the CuNPs prepared using $0.05 \mathrm{gm}$ of copper acetate is unstable when subjected to air for two days, color changed from red to yellow as a result of oxidation of zero valent copper nanoparticles to mono valent $\mathrm{Cu}_{2} \mathrm{O}$. Conclusion

Being rich in terminal reducing groups in addition to the amide groups, NCEC would certainly function as a good stabilizing agent. In combination with this is the polymeric nature of NCEC. Such characteristics of metal nanoparticles, exemplified by the nanosized particles of copper. CuNPs acquired spherical shape even upon using higher concentration of copper acetate to produce colloidal solution containing CuNPs in average size ranging at $25 \mathrm{~nm}$.

\section{References}

1. E. Espino-Pérez, J. Bras, V. Ducruet, A. Guinault, A. Dufresne, S. Domenek, European Polymer Journal, 49, 3144-3154 (2013).

2. N. Bitinis, R. Verdejo, J. Bras, E. Fortunati, J.M. Kenny, L. Torre, M.A. López-Manchado, Carbohydrate polymers, 96, 611-620 (2013).

3. K. Missoum, F. Martoïa, M.N. Belgacem, J. Bras, Industrial Crops and Products, 48, 98-105 (2013).

4. G. Siqueira, J. Bras, A. Dufresne, Langmuir, 26, 402-411 (2009).

5. W. Hu, S. Chen, J. Yang, Z. Li, H. Wang, Carbohydrate polymers, 101, 1043-1060 (2014).

6. M.E. El-Naggar, A.G. Hassabo, A.L. Mohamed, T.I. Shaheen, Journal of colloid and interface science, 498,413-422 (2017).

7. A. Fouda, E. Saad, S.S. Salem, T.I. Shaheen, Microbial pathogenesis, 125, 252-261 (2018).

8. A. Hebeish, T.I. Shaheen, M.E. El-Naggar, International journal of biological macromolecules, 87, 70-76 (2016).

J. Text. Color. Polym. Sci. 16, No. 2 (2019)
9. J. Ramyadevi, K. Jeyasubramanian, A. Marikani, G. Rajakumar, A.A. Rahuman, Materials Letters, 71, 114-116 (2012).

10. L.Q. Pham, J.H. Sohn, C.W. Kim, J.H. Park, H.S. Kang, B.C. Lee, Y.S. Kang, Journal of colloid and interface science, 365, 103-109 (2012).

11. J.P. Ruparelia, A.K. Chatterjee, S.P. Duttagupta, S. Mukherji, Acta Biomaterialia, 4, 707-716 (2008).

12. E. Fortunati, S. Rinaldi, M. Peltzer, N. Bloise, L. Visai, I. Armentano, A. Jiménez, L. Latterini, J.M. Kenny, Carbohydrate polymers, 101, 1122-1133 (2014).

13. A. Hebeish, S. Farag, S. Sharaf, T.I. Shaheen, Cellulose, 21, 3055-3071 (2014).

14. A. Hebeish, S. Farag, S. Sharaf, T.I. Shaheen, Fibers Polym, 16, 276-284 (2015).

15. T.I. Shaheen, H.E. Emam, International journal of biological macromolecules, 107, 1599-1606 (2018).

16. C.-H. Xue, J. Chen, W. Yin, S.-T. Jia, J.-Z. Ma, Applied Surface Science, 258, 2468-2472 (2012).

17. T.V. Duncan, Journal of colloid and interface science, 363, 1-24 (2011).

18. D. Thi My Dung, L. Thi Tuyet Thu, F.-B. Eric, D. Mau Chien, Advances in Natural Sciences: Nanoscience and Nanotechnology, 2, 015009 (2011).

19. Q.-m. Liu, D.-b. Zhou, Y. Yamamoto, R. Ichino, M. Okido, Transactions of Nonferrous Metals Society of China, 22, 117-123 (2012).

20. Journal of Nanotechnology, 2012, (2012) 1.

21. High Temperature, 51, 277 (2013).

22. Spectrochimica Acta Part A: Molecular and Biomolecular Spectroscopy, 110, 108 (2013).

(Received $21 / 10 / 2019$; accepted $15 / 12 / 2019$ ) 


\section{الرتخدام كاربامويل إيثيل السليلوز في حجم النانو لتحضير جسيمات النحاس النانوية

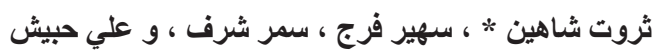

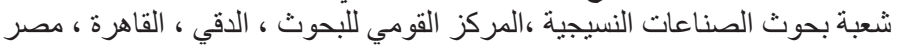

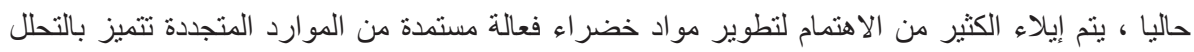

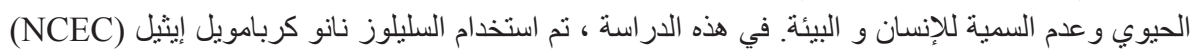

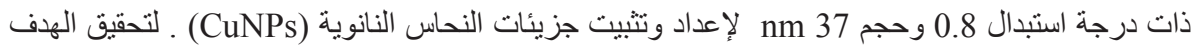

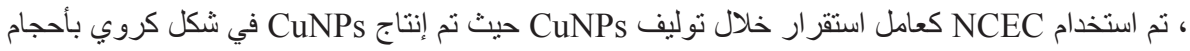

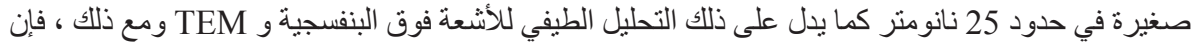
المحاليل الغروية من CuNPs بتركيز ات مختلفة أظهرت ثبات عالي للغاية. 